\title{
Standardized regression-based clinical change score cutoffs for normal pressure hydrocephalus
}

\author{
Alexander Davis ${ }^{1 *}$, Sevil Yasar², Iris Emerman', Seema Gulyani', Kristina Khingelova', Aruna Rao ${ }^{1}$, \\ Lacie Manthripragada ${ }^{3}$, Mark Luciano $^{3}$ and Abhay Moghekar ${ }^{1}$
}

\begin{abstract}
Background: Presently, for patients presenting with suspected Normal Pressure Hydrocephalus (NPH) who undergo temporary drainage of cerebrospinal fluid (CSF) there is no defined model to differentiate chance improvement form clinical significance change at the individual patient level. To address this lack of information we computed standard regression based clinical change models for the 10 Meter Walk Test, Timed Up \& Go, Dual Timed Up \& Go, 6-Minute Walk Test, Mini-Balance Evaluation Systems Test, Montreal Cognitive Assessment, and Symbol Digit Modalities using data from patients with suspected NPH that underwent temporary drainage of CSF. These clinically significant change modes can classify clinically significant improvement following temporary drainage of CSF at the individual patient level. This allows for physicians to differentiate a clinically significant improvement in symptoms from chance improvement.
\end{abstract}

Methods: Data was collected from 323 patients, over the age of 60, with suspected NPH that underwent temporary drainage of CSF with corresponding gait and cognitive testing. McSweeney Standardized Regression Based Clinical Change Models were computed for standard gait and cognitive measures: Timed Up \& Go, Dual Timed Up \& Go, 10 Meter Walk Test, MiniBESTest, 6-Minute Walk Test, Montreal Cognitive Assessment, and Symbol Digit Modalities Test. To assess the discriminate validity of the measures we used correlations, $\mathrm{Chi}^{2}$, and regression analyses.

Results: The clinical change models explained $69-91.8 \%$ of the variability in post-drain performance $(p<0.001)$. As patient scores became more impaired, the percent change required for improvement to be clinically significant increased for all measures. We found that the measures were not discriminate, the Timed Up \& Go was highly related to the 10 Meter Walk Test $\left(r=0.85, R^{2}=0.769-0.738, p<0.001\right)$, MiniBESTest $\left(r=-0.67, R^{2}=0.589-0.734\right.$, $p<0.001)$, and 6 Minute Walk Test $\left(r=-0.77, R^{2}=0.71-0.734, p<0.001\right)$.

Conclusion: Standardized Regression Based Clinically Significant Change Models allow for physicians to use an evidence-based approach to differentiate clinically significant change from chance improvement at the individual patient level. The Timed Up \& Go was shown to be predictive of detailed measures of gait velocity, balance, and endurance.

Keywords: Normal pressure hydrocephalus, Clinical Change, Tests and measurements, Gait, Cognition

\footnotetext{
* Correspondence: ajd@jhmi.edu

${ }^{1}$ Department of Neurology, Johns Hopkins University School of Medicine,

5200 Eastern Ave CTR STE 5100, Baltimore, MD 21224, USA

Full list of author information is available at the end of the article
}

(c) The Author(s). 2020 Open Access This article is licensed under a Creative Commons Attribution 4.0 International License, which permits use, sharing, adaptation, distribution and reproduction in any medium or format, as long as you give appropriate credit to the original author(s) and the source, provide a link to the Creative Commons licence, and indicate if changes were made. The images or other third party material in this article are included in the article's Creative Commons licence, unless indicated otherwise in a credit line to the material. If material is not included in the article's Creative Commons licence and your intended use is not permitted by statutory regulation or exceeds the permitted use, you will need to obtain permission directly from the copyright holder. To view a copy of this licence, visit http://creativecommons.org/licenses/by/4.0/ The Creative Commons Public Domain Dedication waiver (http://creativecommons.org/publicdomain/zero/1.0/) applies to the data made available in this article, unless otherwise stated in a credit line to the data. 


\section{Background}

Idiopathic Normal Pressure Hydrocephalus (NPH) is a neurological condition caused by enlarged communicating ventricles, defined by an Evans index (EI) of at least $0.3[1,2]$. The classic triad of NPH is gait dysfunction, cognitive decline, and urinary incontinence, with gait dysfunction being an essential symptom of the triad [3-5]. One way to assess if a patient will benefit from a shunt is measuring their responsiveness to temporary drainage of cerebrospinal fluid (CSF), either by a lumbar puncture $(30-50 \mathrm{ml})$ or extended lumbar drainage $(300-400 \mathrm{ml})$ [5]. The goal of temporary drainage of CSF it to compare the results of pre-drain and postdrain objective testing to determine if the patient had a meaningful improvement in symptoms [6].

Assessing change in objective gait or cognitive measures following temporary CSF drainage requires a defined model to ensure that patients are selected for shunt surgery in a reliable and valid manner. Grading scales are the primary models used to assess change in score following temporary CSF drainage. Grading scales are efficient for defining improvement at the group level. However, they have not been validated to differentiate a significant change from chance improvement at the individual patient level $[7,8]$. The present study aimed to address this gap of knowledge by establishing standardized clinical change models using data from patients evaluated for suspected NPH to differentiate chance improvement from a clinically significant change at the individual level. Clinically significant change is defined as a change in score on an established clinical measure that is beyond what would be predicted by regression while accounting for measurement error [9]. We will present clinical change models for the 10 Meter Walk Test [10], Timed Up \& Go [11-13], Dual Timed Up \& Go [14, 15], 6-Minute Walk Test [16-18], Mini-Balance Evaluation Systems Test [19], Montreal Cognitive Assessment [20, 21], and Symbol Digit Modalities [22]. Additionally, we plan to assess the discriminate validity of measures used in patients presenting with suspected NPH designed to assess the domains of gait velocity, balance, and endurance.

\section{Methods}

\section{Participants}

A retrospective chart review of 323 patients who underwent temporary drainage of CSF at the Johns Hopkins Center for CSF Disorders. All patients included in the study were over the age of 60 and seen within the departments of Neurosurgery and Neurology, between October 2013 and March 2019. Patients were included in the study if they had cerebral ventriculomegaly and the presence of gait, cognitive, or urinary dysfunction. For this analysis, we did not classify patients as idiopathic NPH as the same criteria are used to assess change in score for both idiopathic and secondary NPH. However, patients that had a brain tumor or subarachnoid hemorrhage were excluded. The study was conducted with the approval of the Johns Hopkins Institutional Review Board. Since this was a retrospective study involving only data extraction and analysis, informed consent was waived by the IRB. Data once extracted was anonymized for analysis.

\section{Outcome measures}

Physical therapists completed all gait assessments, while trained research assistants completed cognitive testing. Gait assessments were administered in hallways with smooth floors. Assistive devices were used when required for safe ambulation. Patients were required to use the same assistive device for all trials. Pre-drain assessments were completed between 1 and $4 \mathrm{~h}$ of the beginning of the drain. Post-drain assessments began when the patient was medically cleared to walk after the drainage procedure, less than $60 \mathrm{~min}$ after LP, and between 1 and $4 \mathrm{~h}$ after ELD. Gait measures were divided into three domains - velocity, balance, and endurance.

\section{Gait velocity}

For all gait velocity measures, patients were instructed to walk, "As quickly as you can, safely." 10 Meter Walk Test (10 MWT): patients started standing up, walked 10 meters in a straight line, and stopped. Timed Up \& Go (TUG): patients started seated in a chair with armrests, stood up, walked 10 feet, turned 180 degrees; walked back and sat down in the chair. Dual TUG: identical to the TUG except while patients walked, they performed a serial subtraction of three. All gait velocity measures used the time required to complete measured to hundredths of a second as the final score.

\section{Endurance}

6-Minute Walk Test (6MWT): Patients walked as far as they were capable of in 6 minutes. The final score for the $6 \mathrm{MWT}$ was total distance walked measured in feet.

\section{Balance}

Mini-Balance Evaluation Systems Test (Mini-BEST): is a dynamic measure of balance consisting of 14 items all scored from 0 to 2 . Patients attempted tasks such as rising from a chair with their arms crossed, attempting to raise their heels off the ground while standing upright, etc. The maximum score was 28 points with a higher total score indicating better balance.

\section{Cognition}

Montreal Cognitive Assessment (MoCA): assesses global cognitive function. The MoCA is scored out of 30 points with higher scores indicating better performance. 
Symbol Digit Modalities Test (SDMT): is a test of visuomotor coordination relying on a combination of attention, processing speed and working memory.

\section{Statistical analyses}

Before defining the data analysis plan, we knew that we had attempted temporary drains on patients with extreme levels of impairment that go beyond what would be consistent with suspected NPH. To address this issue, outliers were removed based on pre-drain scores using the Standard Outlier Formula to trim the data [23]. The MoCA lower bound was 6.5 with an upper bound greater than 30 (removed $n=6$ ). The TUG lower bound was below zero seconds and the upper bound was 51.37 s (removed $n=33$ ). The Dual TUG lower bound was below zero seconds with an upper bound of $77.83 \mathrm{~s}$ (removed $n=17$ ). Ten MWT lower bound was below zero seconds, with an upper bound of $33.1 \mathrm{~s}$ (removed $n=$ 31). No outliers were removed for the SDMT, MiniBEST, or 6MWT.

In a sensitivity analysis to assess if there was a significant difference between LPs and ELDs, we compared Pre-drain scores, Post-drain scores, and percent change of scores using t-tests. After removing outliers, there was no significant difference between LPs and ELDs for the MoCA, TUG, Dual TUG, Mini-BEST and 10 MWT. There was a significant difference between groups at pre-drain for the $6 \mathrm{MWT}$. For patients with a baseline of over $500 \mathrm{ft}$, there was no significant difference in response to temporary drainage for the 6MWT. For this study, LPs $(n=238)$ and ELDs $(n=72)$ were pooled together for analysis. If a patient had undergone multiple temporary drains, only the first drain was used for analysis.

The primary objective of data analysis was to create empirical models for discerning clinically significant change from chance improvement at the individual patient level. Clinically significant change is defined as a change in score on an established clinical measure that is beyond what would be predicted by regression while accounting for measurement error. To create clinical change models, we used the Standardized Regression-Based model (SRB). We chose the SRB model because it best fits the needs of our population because of the wide range of scores at baseline [24]. For calculating the SRB models, we followed procedures described by McSweeney et al., [9] SRB models can use multiple linear regression to predict the posttest score for an individual based on the pretest score and other relevant variables. The predictor variables used in our regression equations were, Pre-drain score, sex, age, BMI, height, Evans index, past medical history of conditions affecting gait, assistive device used, education level, and depression. However, as others have noted, even when significant, the added predictor variables beyond the
Pre-drain (baseline) score did not add any increased predictive value to the SRB models [24-29]. The final models used for all measures were simple SRB models. Once the predicted score has been calculated using the linear regression model, the score can be converted into a change z-score using the following equation: $\mathrm{z}$-score $=(\mathrm{Yo}-\mathrm{Yp}) /$ SEest, Yo is the observed posttest score, Yp is the predicted score and SEest is the standard error of the estimate from the regression equation. For change to be clinically significant, the z-score must exceed \pm 1.64 ( $90 \%$ confidence interval) [30,31].

The secondary objective was to assess the discriminate validity of dividing the gait measures by the domains of velocity, balance, and endurance. To assess if there was a relationship between measures, a correlation matrix using the Pre-drain scores was computed. For measures that were highly correlated $(\mathrm{R}>0.70)$, a Pearson $\mathrm{chi}^{2}$ analysis using the outcome of the temporary drain for each measure was performed (outliers were not removed for the $\mathrm{chi}^{2}$ analysis). For any combination of measures for which $\mathrm{chi}^{2}$ was significant, a regression analysis was performed to assess the relationship between the Predrain to Pre-drain and Post-drain to Post-drain scores of the measures. If the Pre-drain regression analysis was significant $(p<0.05)$, a Post-drain regression analysis was performed. For the regression analyses, models were checked for a quadratic or cubic relationship, and heteroscedasticity. If a model was found to be heteroscedastic, cooks' distance was used with a cutoff of $4 / n$ as a cutoff for overly influential points [32].

\section{Results}

\section{Participants}

Table 1 presents baseline patient demographic data and clinical characteristics including age, race, sex, education, EI, and past medical history that could affect gait (stroke, transient ischemic attack, Parkinson's disease, peripheral neuropathy, osteoarthritis, degenerative joint disease, and spinal disorders).

Patients were predominantly Caucasian (89\%) and highly educated. The mean age was 74.9 years $(\mathrm{SD} \pm 6.4)$, with a mean body mass index (BMI) of $27.75(\mathrm{SD} \pm 4.6)$, $39 \%$ of patients used an assistive device, and $55 \%$ of patients had a past medical history that could affect their gait.

\section{Outcome measures}

Table 2 shows Pre-drain and Post-drain scores for the outcome measures.

The test-retest reliability of the Pre- and Post-drain measures was high, with a reliability coefficient ranging between $0.83-0.96$. The percent change of the mean value between Pre-drain and Post-drain gait measures ranged from 14.48 to $19.18 \%$. For the MoCA, the mean 
Table 1 Baseline demographics and clinical characteristics of (N=323) study participants

\begin{tabular}{ll}
\hline & $\begin{array}{l}\text { Mean (SD) or N (\%) } \\
N=323\end{array}$ \\
\hline Age (years) & $74.88(6.41)$ \\
Sex (male) & $194(60)$ \\
Race (Caucasians) & $287(89)$ \\
Education (years) & \\
$\quad \leq 12$ & $100(31)$ \\
$13-16$ & $120(37)$ \\
$>16$ & $103(32)$ \\
Evans Index (El) & $0.37(0.04)$ \\
Height (meters) & $1.69(0.11)$ \\
Body Mass Index (BMI) & $27.75(4.56)$ \\
Assistive Device & \\
$\quad$ None & $132(41)$ \\
Cane & $89(28)$ \\
$\quad$ Walker & $102(32)$ \\
Past Medical History & $279(55)$ \\
\hline
\end{tabular}

Past Medical History positive for any of the following: stroke, transient ischemic attack, Parkinson's disease, spinal disorders, degenerative joint disease, neuropathy or osteoarthritis

Pre-drain and Post-drain percent change was only $2.98 \%$.

Table 3 shows the SRB equations predicting Postdrain scores using the Pre-drain score for each measure.

Across all measures, patients with minor impairment at Pre-drain required a smaller percent change to reach the threshold of clinically significant change than patients with moderate to high levels of impairment.

For assessing discriminate validity, we found that all baseline gait measures were highly correlated $(r=0.67-$ 0.85) (Table 4).

For the $\mathrm{chi}^{2}$ analysis, we found the TUG was significantly associated with all other gait measures (6MWT

Table 2 Pre-and Post-drain results of cognition, gait, balance, and endurance

\begin{tabular}{llll}
\hline & Pre-drain (SD) & Post-drain Mean (SD) & Pearson R \\
\hline MoCA (points) & $20.49(5.05)$ & $21.10(4.88)$ & 0.83 \\
SDMT (Points) & $21.72(9.41)$ & $22.50(9.55)$ & 0.88 \\
TUG (sec) & $18.64(9.72)$ & $15.94(8.45)$ & 0.91 \\
Dual TUG (sec) & $27.03(16.26)$ & $22.57(12.94)$ & 0.89 \\
10 MWT (sec) & $12.99(5.78)$ & $10.84(4.50)$ & 0.85 \\
Mini-BEST (points) & $14.70(5.26)$ & $17.52(5.20)$ & 0.89 \\
6 MWT (feet) & $792.45(446.87)$ & $918.02(481.71)$ & 0.96 \\
\hline
\end{tabular}

MoCA Montreal Cognitive Assessment, SDMT Symbol Digit Modalities Test, TUG Timed Up \& Go, Dual TUG Dual Timed Up \& Go, 10 MWT 10 Meter Walk Test, Mini-BEST Mini-Balance Evaluation Systems test, 6 MWT 6-Minute Walk test
Table 3 Regression Coefficients for Standardized RegressionBased (SRB) models of cognition, gait, balance, and endurance

\begin{tabular}{|c|c|c|c|c|c|}
\hline & $\beta^{a}$ & $c^{b}$ & $\mathrm{SE}^{\mathrm{C}}$ & R-Squared & $p$ \\
\hline $\begin{array}{l}\text { MoCA (points) } \\
(N=221)\end{array}$ & 0.800 & 4.720 & \pm 0.764 & 0.690 & $<0.001$ \\
\hline $\begin{array}{l}\text { SDMT (points) } \\
(N=205)\end{array}$ & 0.898 & 2.886 & \pm 0.822 & 0.770 & $<0.001$ \\
\hline $\begin{array}{l}\text { TUG (sec) } \\
(N=277)\end{array}$ & 0.787 & 1.273 & \pm 0.458 & 0.826 & $<0.001$ \\
\hline $\begin{array}{l}\text { Dual TUG (sec) } \\
(N=275)\end{array}$ & 0.705 & 3.414 & \pm 0.697 & 0.789 & $<0.001$ \\
\hline $\begin{array}{l}10 \mathrm{MWT}(\mathrm{sec}) \\
(N=273)\end{array}$ & 0.661 & 2.245 & \pm 0353 & 0.724 & $<0.001$ \\
\hline $\begin{array}{l}\text { Mini-BEST (points) } \\
(N=290)\end{array}$ & 0.880 & 4.564 & \pm 0.406 & 0.799 & $<0.001$ \\
\hline $\begin{array}{l}6 \text { MWT (feet) } \\
(N=306)\end{array}$ & 1.031 & 99.887 & \pm 16.153 & 0.918 & $<0.001$ \\
\hline \multicolumn{6}{|c|}{$\begin{array}{l}\text { MoCA Montreal Cognitive Assessment, SDMT Symbol Digit Modalities Test, TUG } \\
\text { Timed Up \& Go, Dual TUG Dual Timed Up \& Go, } 10 \text { MWT } 10 \text { Meter Walk test, } \\
\text { Mini-BEST Mini-Balance Evaluation Systems test, } 6 \text { MWT 6-Minute Walk test } \\
\text { a'Beta (slope) } \\
{ }^{\text {b Constant }} \\
\text { 'Standard error of the estimate }\end{array}$} \\
\hline
\end{tabular}

$P<0.001 ; 10$ MWT $P<0.001$; Mini-BEST $P=0.023$ ). When applying regressions models using TUG as the predictor variable, there was a quadratic relationship with all other dependent variables.

Table 5 shows for Pre-drain regressions of TUG, Mini-BEST $\left(C=27.278, \beta_{\mathrm{TUG}}\right.$ Pre-drain $=-0.902, \beta_{\mathrm{TUG}}$ Pre-drain ${ }^{2}=0.011, \quad \mathrm{SE} \pm 1.096, \quad$ R-squared $=0.553$, $P<0.001)$ and 6 MWT $\left(C=2089.879, \beta_{\mathrm{TUG}}\right.$ Pre-drain $=-$ 95.028, $ß_{\text {TUG Pre-drain }}{ }^{2}=1.246, \mathrm{SE}+70.744, \mathrm{R}$-squared $=$ $0.71, P<0.001)$ were both highly significant and homoscedastic.

The $10 \mathrm{MWT}$ was also highly significant at pre-drain $\left(C=.974, \beta_{\text {TUG Pre-drain }}=0.782, \beta_{\text {TUG Pre-drain }}{ }^{2}=-0.007\right.$, $\mathrm{SE} \pm 0.798, \mathrm{R}$-squared $=.769, P<0.001)$ but heteroscedastic after influential points were removed. For Postdrain regressions of TUG, the Mini-BEST $(\mathrm{C}=28.679$, $\beta_{\text {TUG Post-drain }}=-0.854, \quad \beta_{\text {TUG }}$ Post-drain ${ }^{2}=0.009, \quad \mathrm{SE} \pm$ 0.799, R-squared $=0.589, P<0.001)$ and $6 \mathrm{MWT}(\mathrm{C}=$

Table 4 Discriminate validity Pre-drain correlations of cognition, gait, balance, and endurance

\begin{tabular}{llllll}
\hline & MoCA & TUG & $10 \mathrm{MWT}$ & Mini-BEST & $6 \mathrm{MWT}$ \\
\hline MoCA (points) & 1 & & & & \\
TUG (sec) & $-0.33^{* * *}$ & 1 & & & \\
$\mathbf{1 0}$ MWT (sec) & $-0.30^{* * *}$ & $0.85^{* * *}$ & 1 & & \\
Mini-BEST (points) & $0.39^{* * *}$ & $-0.67^{* * *}$ & $-0.68^{* * *}$ & 1 & \\
$\mathbf{6}$ MWT (feet) & $0.33^{* * *}$ & $-0.77^{* * *}$ & $-0.80^{* * *}$ & $-.72^{* * *}$ & 1 \\
\hline
\end{tabular}

MoCA Montreal Cognitive Assessment, TUG Timed Up \& Go, 10 MWT 10 Meter Walk test, Mini-BEST Mini-Balance Evaluation Systems test, 6 MWT 6-Minute Walk test

$p<0.05$ *

$p<0.01$ **

$p<0.001 * * *$ 
Table 5 Discriminate validity regression coefficients for the timed up \& go at pre-drain and post-drain

\begin{tabular}{|c|c|c|c|c|c|c|}
\hline & $\beta^{a}$ & $\beta^{b}$ & $C^{c}$ & $\mathrm{SE}^{\mathrm{d}}$ & R-Squared & $p$ \\
\hline MiniBEST Pre-drain $(N=254)$ & -0.902 & 0.011 & 27.278 & \pm 1.096 & 0.553 & $<0.001$ \\
\hline 6 MWT Pre-drain $(N=264)$ & -95.028 & 1.246 & 2089.879 & \pm 70.744 & 0.71 & $<0.001$ \\
\hline 10 MWT Pre-drain $(N=242)$ & 0.782 & 0.007 & 0.974 & \pm 0.798 & 0.769 & $<0.001$ \\
\hline MiniBEST Post-drain $(N=265)$ & -0.854 & 0.009 & 28.679 & \pm 0.799 & 0.589 & $<0.001$ \\
\hline 6 MWT Post-drain $(\mathrm{N}=264)$ & -116.008 & 1.651 & 2307.064 & \pm 66.163 & 0.734 & $<0.001$ \\
\hline 10 MWT Post-drain $(N=243)$ & 0.441 & 0.001 & 3.606 & \pm 0.375 & 0.738 & $<0.001$ \\
\hline
\end{tabular}

Mini-BEST Mini-Balance Evaluation Systems test, 6 MWT 6-Minute Walk test, 10 MWT 10 Meter Walk test

${ }^{\mathrm{a}}$ Beta Timed UP \& GO

${ }^{\mathrm{b}}$ Beta Timed UP \& GO Squared

${ }^{\mathrm{c} C o n s t a n t}$

${ }^{d}$ Standard error of the estimate

2307.064, $\aleph_{\text {TUG }}$ Post-drain $=-116.008, \beta_{\text {TUG }}$ Post-drain ${ }^{2}=$ 1.651, $\mathrm{SE} \pm 66.163, \mathrm{R}$-squared $=0.734, P<0.001$ ) were both highly significant. After influential points were removed both analyses were homoscedastic. The $10 \mathrm{MWT}$ was highly significant $\left(C=3.606, \beta_{\mathrm{TUG}}\right.$ Post-drain $=0.441$, $\beta_{\text {TUG }}$ Post-drain ${ }^{2}=0.001, \quad \mathrm{SE} \pm 0.375, \quad$ R-squared $=0.738$, $P<0.001)$ at Post-drain and heteroscedastic after influential points were removed.

\section{Discussion}

In our study, we have created SRB clinical change models for assessing clinically significant change for patients undergoing CSF drainage as part of an evaluation for suspected NPH for the TUG, Dual TUG, 10 MWT, Mini-BEST, 6MWT, MoCA, and SDMT. Clinically significant change is defined as change on an established clinical measure that is beyond what would be predicted by regression while accounting for measurement error. Clinical change models can differentiate clinically significant change from chance improvement at the individual patient level. The most novel finding was that the percent change required for clinically significant change is not fixed across the range of impairment. The percent change in improvement increases as patients become more impaired. For the tests of discriminate validity, we found that the TUG is significantly related to both predrain and post-drain measures of the Mini-BEST, 6 MWT and, 10 MWT. Our findings show that these measures are not discriminate when used in the suspected NPH population.

When evaluating patients for possible $\mathrm{NPH}$, the primary objective is to determine if there was a significant change in the patient's symptoms following temporary drainage of CSF. Many different scales have attempted to quantify change following temporary CSF drainage. The vast majority of the scales are grading scales [7, 33-37]. Grading scales use categorical cutoffs to separate patients based on their level of impairment. After the temporary CSF drainage, if the patients' Post-drain scores are within a less impaired category, they are considered improved. One commonly used rating scale for NPH was created using data from geriatric normative data. This scale assesses $\mathrm{NPH}$ using four separate domains (gait, neuropsychological, balance, and continence), all normalized to a 100point scale. For a patient to be considered improved, they have to improve by greater than four points overall [7]. The limitation of this grading scale and others created for $\mathrm{NPH}$ is that it does not have an empirical method for differentiating chance improvement from a significant change at an individual patient level. The criteria for improvement in this grading scale is based on summed overall improvement across all four domains. This allows for change in score that is due to chance to contribute towards perceived improvement, thus to the recommendation for shunt surgery.

In this study, we attempted to address this issue by creating SRB clinically significant change models for common gait and cognitive measures (TUG, Dual TUG, 10 MWT, Mini-BEST, MoCA, SDMT, and $6 \mathrm{MWT}$ ) using data collected from patients presenting with suspected NPH that underwent temporary drainage of CSF. Incorporating clinical change model brings an empirical approach to the selection of individual patients for shunt surgery. Clinically significant change models allow physicians to make an evidenced based decision about the clinical significance of change following temporary drainage of CSF.

For temporary drains of CSF, the TUG was shown to be an efficient measure of gait for patients presenting with suspected NPH. The TUG does not require a trained physical therapist and can be administered by clinical staff in approximately 3 minutes. It is a reliable predictor of shunt outcome in NPH patients [38-40]. In our analysis, the TUG was significantly related to detailed measures of balance, endurance, and gait velocity.

This study has both strengths and limitations. Strengths include a large number of patients with detailed and well-established quantitative measures of several gait and cognitive measures. The high test-retest reliability of the measures allows for reliable clinical 
change models to be computed. Limitations include the unknown sensitivity and specificity of shunt outcomes for patients selected based on the clinical change models. To address this lack of information a study is planned to use the clinical change models in the center for CSF disorders to select patients for shunt surgery and assess both the short and long-term shunt outcome of the patients. As well, we intend to establish Minimal Clinically Important Difference models for shunted patients to assess the efficacy of shunting patients at both the individual and group levels.

\section{Conclusion}

Standardized Regression Based Clinically Significant Change Models allow for physicians to use an evidenced based approach to differentiate clinically significant change from chance improvement at the individual patient level. The Timed Up \& Go was shown to be predictive of detailed measures of gait velocity, balance, and endurance.

\section{Abbreviations}

NPH: Normal Pressure Hydrocephalus; CSF: Cerebrospinal Fluid; El: Evans index; 10 MWT: 10 meter walk test; TUG: Timed Up \& Go; 6MWT: 6-Minute Walk Test; Mini-BEST: Mini-Balance Evaluation Systems Test; MoCA: Montreal Cognitive Assessment; SDMT: Symbol Digit Modalities Test

\section{Acknowledgments}

Not applicable.

\section{Authors' contributions}

AD computed the models, wrote the manuscript, and designed the study. SY contributed to the design of the study and edited the manuscript. IE assisted in data analysis and edited the manuscript. SG, KK, AR, LM, and ML collected patient data and contributed to the manuscript. AM conceptualized the study and edited the manuscript. All authors contributed to subsequent drafts and approved the final manuscript.

\section{Funding}

This study was funded by philanthropic contributions made by the Lantry Family Foundation and the Myers Family Foundation. These played no role in the design of the study, collection, analysis, interpretation of data, or in writing the manuscript.

\section{Availability of data and materials}

Anonymized raw data will be made available upon reasonable request.

\section{Ethics approval and consent to participate}

This study was approved by the Johns Hopkins IRB: Cerebrospinal Fluid Disorders Biorepository \& Adult Hydrocephalus Clinical Research Network NA_00029413. Since this was a retrospective study involving only data extraction and analysis, informed consent was waived by the IRB. Data once extracted was anonymized for analysis.

\section{Consent for publication}

Not applicable.

\section{Competing interests}

Alexander Davis- Reports no disclosures.

Sevil Yasar- Reports no disclosures.

Iris Emerman- Reports no disclosures.

Seema Gulyani- Reports no disclosures.

Kristina Khingelova- Reports no disclosures.

Aruna Rao- Reports no disclosures.

Lacie Manthripragada- Reports no disclosures.
Mark Luciano- Reports no disclosures.

Abhay Moghekar- Member of the Medical Advisory Board of the

Hydrocephalus Association - not paid.

\section{Author details}

${ }^{1}$ Department of Neurology, Johns Hopkins University School of Medicine, 5200 Eastern Ave CTR STE 5100, Baltimore, MD 21224, USA. ²Department of Medicine, Johns Hopkins University School of Medicine, Baltimore, MD, USA. ${ }^{3}$ Department of Neurosurgery, Johns Hopkins University, Baltimore, MD, USA.

Received: 10 February 2020 Accepted: 7 April 2020

Published online: 16 April 2020

References

1. Damasceno BP. Neuroimaging in normal pressure hydrocephalus. Dement Neuropsychol. 2015;9(4):350-5 [cited 2019 Jun 10]; Available from: http://www.ncbi.nlm.nih.gov/pubmed/29213984.

2. Toma AK, Holl E, Kitchen ND, Watkins LD. Evans' index revisited: The need for an alternative in normal pressure hydrocephalus. Neurosurgery. 2011; 68(4):939-44.

3. Adams RD, Fisher CM, Hakim S, Ojemann RG, Sweet WH. Symptomatic occult Hydrocephalus with normal cerebrospinal-fluid pressure. N Engl J Med. 1965;273(3):117-26. [cited 2018 Jul 9]. https://doi.org/10.1056/ NEJM196507152730301.

4. Abram K, Bohne S, Bublak P, Karvouniari P, Klingner CM, Witte OW, et al. The Effect of Spinal Tap Test on Different Sensory Modalities of Postural Stability in Idiopathic Normal Pressure Hydrocephalus. Dement Geriatr Cogn Dis Extra. 2016;6(3):447-57 [cited 2018 Jul 9]; Available from: http://www.ncbi. nlm.nih.gov/pubmed/27790243.

5. Marmarou A, Black P, Bergsneider M, Klinge P, Relkin N. Guidelines for management of idiopathic normal pressure hydrocephalus: Progress to date In: Acta Neurochirurgica, Supplementum. Springer, Wien; 2005:237-240.

6. Wikkelsø C, Andersson H, Blomstrand C, Lindqvist G. The clinical effect of lumbar puncture in normal pressure hydrocephalus. J Neurol Neurosurg Psychiatry. 1982;45(1):64-9 [cited 2019 Jun 10]; Available from: http://www. ncbi.nlm.nih.gov/pubmed/7062072.

7. Hellström $P$, Klinge $P$, Tans J, Wikkelsø C. A new scale for assessment of severity and outcome in iNPH. Acta Neurol Scand. 2012;126(4):229-37. [cited 2019 Jun 10]. https://doi.org/10.1111/j.1600-0404.2012.01677.x.

8. Meier U. The grading of normal pressure hydrocephalus. Biomed Tech (Berl). 2002;47(3):54-8 [cited 2019 Jun 10]; Available from: http://www.ncbi.nlm.nih. gov/pubmed/11977443.

9. McSweeny AJ, Naugle RI, Chelune GJ, Lüders H. "T Scores for Change": An illustration of a regression approach to depicting change in clinical neuropsychology. Clin Neuropsychol. 1993;7(3):300-12. [cited 2019 Jun 9]. https://doi.org/10.1080/13854049308401901.

10. Kim H-J, Park I, Lee HJ, Lee $\mathrm{O}$. The reliability and validity of gait speed with different walking pace and distances against general health, physical function, and chronic disease in aged adults. J Exerc Nutr Biochem. 2016; 20(3):46-50 [cited 2019 Jun 11]; Available from: http://www.ncbi.nlm.nih. gov/pubmed/27757387.

11. Podsiadlo D, Richardson S. The Timed "Up \&Amp; Go": a test of basic functional mobility for frail elderly persons. J Am Geriatr Soc. 1991;39(2):142-8. [cited 2018 Sep 8]. https://doi.org/10.1111/j.1532-5415.1991.tb01616.x.

12. Barry E, Galvin R, Keogh C, Horgan F, Fahey T. Is the Timed Up and Go test a useful predictor of risk of falls in community dwelling older adults: a systematic review and meta- analysis. BMC Geriatr. 2014;14(1):14 [cited 2018 Jul 9]; Available from: http://www.ncbi.nlm.nih.gov/pubmed/24484314.

13. Huang S-L, Hsieh C-L, Wu R-M, Tai C-H, Lin C-H, Lu W-S. Minimal detectable change of the timed "Up \&Amp; Go" test and the dynamic gait index in people with parkinson disease. Phys Ther. 2011;91(1):114-21 [cited 2018 Sep 8]; Available from: http://www.ncbi.nlm.nih.gov/pubmed/20947672.

14. Allali G, Laidet M, Beauchet O, Herrmann FR, Assal F, Armand S. Dual-task related gait changes after CSF tapping: a new way to identify idiopathic normal pressure hydrocephalus. J Neuroeng Rehabil. 2013;10(1):117 [cited 2018 Sep 9]; Available from: http://www.ncbi.nlm.nih.gov/pubmed/24359487.

15. Allali G, Laidet M, Armand S, Momjian S, Marques B, Saj A, et al. A combined cognitive and gait quantification to identify normal pressure hydrocephalus from its mimics: The Geneva's protocol. Clin Neurol Neurosurg. 2017;160:5-11 [cited $2018 \mathrm{Jul}$ 23]: Available from: https:/www sciencedirect.com/science/ article/pii/S0303846717301671. 
16. ATS Committee on Proficiency Standards for Clinical Pulmonary Function Laboratories. ATS statement guidelines for the six-minute walk test. Am J Respir Crit Care Med. 2002;166(1):111-7. [cited 2018 Oct 30]. https://doi.org/ 10.1164/ajrccm.166.1.at1102.

17. Goldman MD, Marrie RA, Cohen JA. Evaluation of the six-minute walk in multiple sclerosis subjects and healthy controls. Mult Scler J. 2008;14(3):38390. [cited 2018 Sep 9]. https://doi.org/10.1177/1352458507082607.

18. Savci S, Inal-Ince D, Arikan H, Guclu-Gunduz A, Cetisli-Korkmaz N, Armutlu K, et al. Six-minute walk distance as a measure of functional exercise capacity in multiple sclerosis. Disabil Rehabil. 2005;27(22):1365-71. [cited 2018 Sep 9]. https://doi.org/10.1080/09638280500164479.

19. Yingyongyudha A, Saengsirisuwan V, Panichaporn W, Boonsinsukh R. The Mini-Balance Evaluation Systems Test (Mini-Bestest) demonstrates higher accuracy in identifying older adult participants with history of falls than do the bestest, berg balance scale, or timed up and go test. J Geriatr Phys Ther. 2016;39(2):64-70 [cited 2018 Jul 27]; Available from: http://www.ncbi. nlm.nih.gov/pubmed/25794308.

20. Nasreddine ZS, Phillips NA, Bédirian V, Charbonneau S, Whitehead V, Collin I, et al. The montreal cognitive assessment, moca: a brief screening tool for mild cognitive impairment. J Am Geriatr Soc. 2005;53(4):695-9 [cited 2019 may 26]; Available from: http://www.ncbi.nlm.nih.gov/pubmed/15817019.

21. Maust D, Cristancho M, Gray L, Rushing S, Tjoa C, Thase ME. Psychiatric rating scales. Handb Clin Neurol. 2012;106:227-37 [cited 2019 Jun 10]; Available from: https:/www.sciencedirect.com/science/article/pii/ B9780444520029000139?via\%3Dihub.

22. Benedict RH, DeLuca J, Phillips G, LaRocca N, Hudson LD, Rudick R, et al. Validity of the Symbol Digit Modalities Test as a cognition performance outcome measure for multiple sclerosis. Mult Scler. 2017;23(5):721-33 [cited 2019 Sep 9]; Available from: http://www.ncbi.nlm.nih.gov/pubmed/28206827.

23. Kwak SK, Kim JH. Statistical data preparation: management of missing values and outliers. Korean J Anesthesiol. 2017;70(4):407-11 [cited 2019 Jun 8]; Available from: http://www.ncbi.n/m.nih.gov/pubmed/28794835.

24. Hinton-Bayre AD. Clarifying discrepancies in responsiveness between reliable change indices. Arch Clin Neuropsychol. 2016;31(7):754-68 [cited 2019 Jun 9]; Available from: http://www.ncbi.nlm.nih.gov/pubmed/27590303.

25. Temkin NR, Heaton RK, Grant I, Dikmen SS. Detecting significant change in neuropsychological test performance: a comparison of four models. J Int Neuropsychol Soc. 1999;5(4):357-69 [cited 2019 Jun 9]; Available from: http://www.ncbi.nlm.nih.gov/pubmed/10349298.

26. Heaton RK, Temkin N, Dikmen S, Avitable N, Taylor MJ, Marcotte TD, et al. Detecting change: A comparison of three neuropsychological methods, using normal and clinical samples. Arch Clin Neuropsychol. 2001;16(1):75-91 [cited 2019 Jun 9]; Available from: https://www.sciencedirect.com/science/ article/pii/S0887617799000621?via\%3Dihub.

27. Frerichs $\mathrm{R}$, Tuokko H. A comparison of methods for measuring cognitive change in older adults. Arch Clin Neuropsychol. 2005;20(3):321-33. [cited 2019 Jun 9]. https://doi.org/10.1016/j.acn.2004.08.002.

28. Hinton-Bayre AD. Deriving reliable change statistics from test-retest normative data: comparison of models and mathematical expressions. Arch Clin Neuropsychol. 2010;25(3):244-56. [cited 2019 Jun 9]. https://doi.org/10. 1093/arclin/acq008.

29. Duff K. Evidence-based indicators of neuropsychological change in the individual patient: relevant concepts and methods. Arch Clin Neuropsychol. 2012;27(3):248-61 [cited 2019 Jun 9]; Available from: http://www.ncbi.nlm. nih.gov/pubmed/22382384.

30. Hermann BP, Seidenberg M, Schoenfeld J, Peterson J, Leveroni C, Wyler AR. Empirical techniques for determining the reliability, magnitude, and pattern of neuropsychological change after epilepsy surgery. Epilepsia. 1996;37(10): 942-50 [cited 2019 Jun 9]; Available from: http://www.ncbi.nlm.nih.gov/ pubmed/8822692

31. Johnson EK, Dow C, Lynch RT, Hermann BP. Measuring clinical significance in rehabilitation research. Rehabil Counsel Bull. 2006 [cited 2019 Jun 9]. https://doi.org/10.1177/00343552060500010501.

32. Cook DR. American society for quality detection of influential observation in linear regression detection of influential observation in linear regression, vol. 19: Technometrics; 1977. [cited 2019 Jul 7]. Available from: http://www. stat.ucla.edu/ nchristo/statistics100C/1268249.pdf.

33. Black PM. Idiopathic normal-pressure hydrocephalus. J Neurosurg. 1980; 52(3):371-7 [cited 2019 Jun 22]; Available from: http://www.ncbi.nlm.nih gov/pubmed/7359191.
34. Krauss JK, Regel JP. The predictive value of ventricular CSF removal in normal pressure hydrocephalus. Neurol Res. 1997;19(4):357-60 [cited 2019 Jun 22]; Available from: http://www.ncbi.nlm.nih.gov/pubmed/9263213.

35. Kiefer M, Eymann $R$, Meier U. Five years experience with gravitational shunts in chronic hydrocephalus of adults. Acta Neurochir (Wien). 2002;144(8):75567. [cited 2019 Jun 22]. https://doi.org/10.1007/s00701-002-0977-7.

36. Kubo Y, Kazui H, Yoshida T, Kito Y, Kimura N, Tokunaga $H$, et al. Validation of grading scale for evaluating symptoms of idiopathic normal-pressure hydrocephalus. Dement Geriatr Cogn Disord. 2008;25(1):37-45 [cited 2019 Jun 22]; Available from: http://www.ncbi.nlm.nih.gov/pubmed/18025828.

37. Poca MA, Mataró M, Matarín M, Arikan F, Junqué C, Sahuquillo J. Good outcome in patients with normal-pressure hydrocephalus and factors indicating poor prognosis. J Neurosurg. 2005;103(3):455-63 [cited 2019 Jun 22]; Available from: http://www.ncbi.nlm.nih.gov/pubmed/16235677.

38. Mendes GAS, de Oliveira MF, FCG P. The Timed Up and Go test as a diagnostic criterion in normal pressure hydrocephalus. World Neurosurg. 2017;105:456-61 [cited 2019 Jul 7]; Available from: https://www. sciencedirect.com/science/article/pii/S1878875017308392?via\%3Dihub.

39. Yamada S, Ishikawa M, Miyajima M, Nakajima M, Atsuchi M, Kimura T, et al. Timed up and go test at tap test and shunt surgery in idiopathic normal pressure hydrocephalus. Neurol Clin Pract. 2017;7(2):98-108 [cited 2019 Jul 7]. Available from: http://www.ncbi.nlm.nih.gov/pubmed/29185546.

40. Herman T, Giladi N, Hausdorff JM. Properties of the "timed up and go" test: more than meets the eye. Gerontology. 2011;57(3):203-10 [cited 2019 Jul 7]; Available from: http://www.ncbi.nlm.nih.gov/pubmed/20484884.

\section{Publisher's Note}

Springer Nature remains neutral with regard to jurisdictional claims in published maps and institutional affiliations.
Ready to submit your research? Choose BMC and benefit from:

- fast, convenient online submission

- thorough peer review by experienced researchers in your field

- rapid publication on acceptance

- support for research data, including large and complex data types

- gold Open Access which fosters wider collaboration and increased citations

- maximum visibility for your research: over $100 \mathrm{M}$ website views per year

At BMC, research is always in progress.

Learn more biomedcentral.com/submissions 